\title{
Gastro-bronchial fistula
}

\author{
Anthony J. B. Missen \\ M.B., F.R.C.S.
}

JAMES PEMBERTON
M.R.C.P., D.M.R.D.

\author{
ANDREW BOON \\ B.Sc., M.B., B.S.
}

St Bartholomew's Hospital, London

\begin{abstract}
Summary
1. Gastro-bronchial fistula is a rare condition occurring most commonly as a complication of a subphrenic abscess.

2. Other causes include trauma and necrosis within an infiltrating neoplasm.

3. The treatment of those fistulae which are secondary to a subphrenic abscess should be by drainage of the abscess, jejunal tube feeding and continuous gastric aspiration.
\end{abstract}

OF the various gastric fistulae described in the literature those communicating with the bronchi appear to be among the rarest. Aird (1957) devotes only four lines to the subject while Milne and Thompson (1970) state that a careful search of medical literature failed to reveal any reference to the condition. This is somewhat misleading as the literature since 1960 contains seven case reports and a number of earlier references have been encountered in the preparation of this paper.

It would appear that gastro-bronchial fistulae may arise in one of four ways (Table 1). The largest group develop as a complication of a subphrenic abscess extending through the diaphragm to form an empyema, or lung abscess, which in turn drains into the bronchial tree. The formation of a bronchial fistula in this way is a well recognized complication of subphrenic abscess and occurs in about $10 \%$ cases (Ochsner and Graves, 1933; Wetterfors, 1960). Where the subphrenic abscess has arisen from perforation of the stomach, or when it causes necrosis of a part of the stomach wall, a gastro-bronchial fistula may ensue.

A somewhat similar process accounts for the second group which develops as a result of the perforation of a stomach incarcerated in a diaphragmatic hernia. A perigastric abscess lying above the diaphragm occurs and extends into the lung until it eventually drains via the bronchial tree.
A third group results from necrosis in an infiltrating carcinoma which may be either a primary tumour of the stomach or a tumour arising in a nearby site which infiltrates the stomach and also extends via the diaphragm into the lower lobe of the left lung. Tumours behaving in this way may also involve adjacent loops of bowel, particularly the colon, with the formation of even more complex fistula tracks.

The fourth type of gastro-bronchial fistula is traumatic in origin resulting from rupture of the diaphragm associated with damage to both the lung and the stomach.

The present case which was secondary to a carcinoma of the pancreas appears to be a considerable rarity and worthy of record on that account.

\section{Case history}

The patient, G.W., aged 68, was admitted on February 221972 via the Casualty Department. He complained of breathlessness, lethargy and weight loss over the past 2 years. Eight years earlier he had a persistent cough and two haemoptyses; bronchoscopy at that time showed nothing abnormal and although the cough persisted the patient had no further haemoptyses.

On examination, dullness on percussion and reduced air entry over both lung bases were noted. There was also marked clubbing of the fingers. Laboratory investigations revealed a hypochromic anaemia (Hb $10 \mathrm{~g} / 100 \mathrm{ml})$, a raised sedimentation rate (111 $\mathrm{mm}$ in first hour), an alkaline phosphatase of 204 units, serum calcium (corrected) $10.5 \mathrm{mg} / 100$ $\mathrm{ml}$ and serum phosphate of $4.4 \mathrm{mg} / 100 \mathrm{ml}$. The sputum was purulent and blood-stained yielding a growth of coliform organisms. No malignant cells were found on cytological examination.

Chest X-ray showed some shrinkage of the left lower lobe with a circular opacity in the right middlc lobe. Tomography was carried out and the opacity found to be irregular in outline. There was no hilar 
TABLE 1. The aetiology of gastro-bronchial fistula

\begin{tabular}{|c|c|c|}
\hline Author & Group & Observations \\
\hline Mason, 1965 & 1. Subphrenic abscess & $\begin{array}{l}\text { Gastro-broncho-colic fistula. Drainage of abscess and gastric } \\
\text { aspiration. Recovered. }\end{array}$ \\
\hline Hathirat, 1969 & & $\begin{array}{l}\text { Abscess drained. Duodenal tube feeding for } 5 \text { weeks. Did } \\
\text { not heal. Refused surgery. }\end{array}$ \\
\hline Jackiewicz, 1969 & & $\begin{array}{l}\text { Perforated G.U. Wedge resection of lung and stomach with } \\
\text { long term drainage. Recovered. }\end{array}$ \\
\hline Gimes, 1970 & & Perforated G.U. Abscess drained (6 weeks). Recovered. \\
\hline Milne and Thomson, 1970 & & Followed gastric surgery. Died. \\
\hline $\begin{array}{l}\text { Liavaag, } 1948 \\
\text { Efskind, } 1953\end{array}$ & 2. Perigastric abscess & $\begin{array}{l}\text { Recurrent diaphragmatic hernia with perforation of incar- } \\
\text { cerated stomach. Left lower lobectomy and closure of fistula. }\end{array}$ \\
\hline Urizza and Ramirez Gama, 1954 & & $\begin{array}{l}\text { Anterior diaphragmatic hernia with incarceration of } \\
\text { stomach. }\end{array}$ \\
\hline Missen et al., 1974 & 3. Neoplastic & Carcinoma of pancreas. Died. \\
\hline Gericke, 1957 & 4. Trauma & Wounded by bomb. Diagnosed after 12 years. No operation. \\
\hline Seyfarth, 1959 & & $\begin{array}{l}\text { Grenade wound } 1942 \text {. Symptoms } 1945-49 \text {. No operation. } \\
\text { Remained at work. }\end{array}$ \\
\hline Moron et al., 1969 & & $\begin{array}{l}\text { Splinter wound left costal margin. Repair of diaphragmatic } \\
\text { wound. Symptoms persisted. Further surgery refused. }\end{array}$ \\
\hline
\end{tabular}
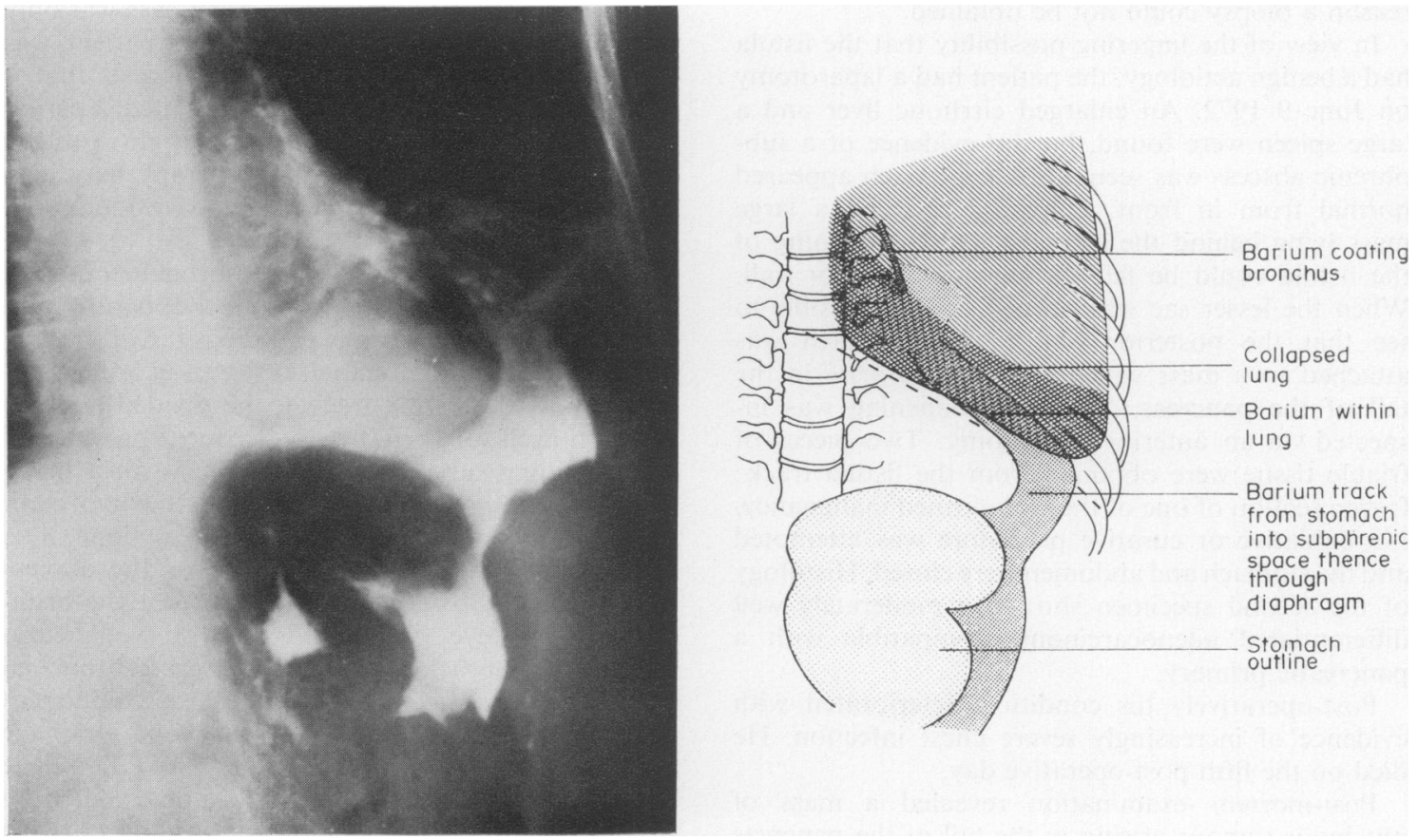

Fig. I. X-ray and explanatory line drawing to illustrate barium-filled fistula track.

lymphadenopathy and the main bronchi were all patent. The appearances were compatible with a primary or secondary neoplasm. The X-ray appearances were unchanged after 2 months and the sputum remained purulent despite the use of appropriate antibiotics.
Bronchoscopy on May 111972 showed no evidence of carcinoma. It was thought that bronchiectasis might account for the clinical picture, but the patient's general condition precluded bronchography.

Twelve weeks after admission, the patient was 
observed to cough up a quantity of putrefying material which resembled stomach contents and the possibility of a tracheo-oesophageal fistula was considered. A barium swallow showed no abnormality with the patient upright. However, when the patient was placed in the supine position, the barium filled the fundus of the stomach and then passed via an irregular channel to enter the bronchi of the left lower lobe (Fig. 1). It was suggested that a carcinoma of the fundus ventriculi had perforated with the formation of a subphrenic abscess which had in turn drained spontaneously into the left lower lobe bronchi via the diaphragm.

Gastroscopy was performed on June 51972 to try to confirm the presence of a carcinoma of the stomach. There was no evidence of carcinoma in the body or fundus. The opening of the fistula was easily seen, but the adjacent mucosa was normal and the appearances were more in keeping with a benign chronic gastric ulcer.

Difficulty was experienced in trying to inflate the stomach as the air escaped via the fistula and for this reason a biopsy could not be obtained.

In view of the lingering possibility that the fistula had a benign aetiology, the patient had a laparotomy on June 9 1972. An enlarged cirrhotic liver and a large spleen were found, but no evidence of a subphrenic abscess was seen and the stomach appeared normal from in front. Palpation revealed a large mass lying behind the stomach and the opening of the fistula could be felt through the anterior wall. When the lesser sac was opened, it was possible to see that the posterior wall of the stomach was attached to a mass which appeared to arise in the tail of the pancreas. The fistula opening was inspected via an anterior gastrotomy. Two pieces of friable tissue were obtained from the fistula track: frozen section of one of these confirmed malignancy. No palliative or curative procedure was attempted and the stomach and abdomen were closed. Histology of the second specimen showed a moderately well differentiated adenocarcinoma compatible with a pancreatic primary.

Post-operatively his condition deteriorated with evidence of increasingly severe chest infection. $\mathrm{He}$ died on the fifth post-operative day.

Post-mortem examination revealed a mass of mucinous tumour arising in the tail of the pancreas and involving the hilum of the spleen and the posterior wall of the stomach which was infiltrated in the cardiac and pyloric regions with the production of large fistulae at both these sites. The tumour also involved the colon close to the splenic flexure and was beginning to ulcerate the colonic mucosa. The tumour had extended upwards through the diaphragm to invade the left lung base in which there was a cavity $2 \mathrm{~cm}$ in diameter communicating with the tumour and lower lobe bronchi. The middle lobe of the right lung contained discrete, firm, white areas up to $2 \mathrm{~cm}$ in diameter which appeared to be bronchopneumonic consolidation.

Histological examination of the tumour confirmed its pancreatic origin.

\section{Discussion}

This rare and rather bizarre condition is not difficult to diagnose when the patient starts to cough up food residues provided these are recognized. In retrospect this man's persistent chest infection with minimal response to any form of antibiotic therapy is easily understood. It is also probable that the shadow in the right lung and the broncho-pneumonic nodules found at post mortem were manifestations of an unusual form of aspiration pneumonia.

Efskind (1953) makes the point that in fistulae between the upper gastro-intestinal tract and the air passages the posture of the patient during barium studies is important as a routine swallow in the erect position commonly fails to demonstrate any abnormality. The fistula track in the present case was only filled with contrast medium when the patient was placed in the supine position. This suggests that if surgical repair of the fistula is contemplated, a periog of pre-operative nursing in the upright posture coupled with intensive antibiotic therapy may hel to minimize the aspiration of food residues ant consequent infection.

The surgical treatment of gastro-bronchial fistulae once diagnosed will depend on the nature and extent of the underlying pathology. Aird (1957) suggests than an abdominal exploration will sometimes allow the fistula track to be divided and the stomach itself repaired, but the frequent presence of long standing sub-diaphragmatic sepsis must make this a difficult procedure. In the treatment of subphrenic abscess with bronchial fistula alone it is established that adequate drainage of the abscess usually results in spontaneous closure of the bronchial fistula (Beye, 1932; Boyd, 1959). It would seem logical to approach the problem of gastrobronchial fistulae in the same way, but the gastric component of the fistula complicates the issue and drainage alone may not be curative (Mason, 1965). Drainage of the subphrenic abscess must be supplemented by drainage of the stomach and tube feeding into the jejunum.

Insertion of a suitable double lumen tube (e.g. Kay's catheter) via a single gastrostomy will allow continuous gastric aspiration and simultaneous attention to the patient's nutritional needs. Gastric suction was maintained for 23 days in the case reported by Mason and it appears that the bronchial fistula became sealed off during that time. An improved response to antibiotics and physiotherapy 
might be expected when the bronchial fistula closes and it would seem wise to continue these measures. The gastric fistula may persist for a period and the subphrenic drain should be left in place until the cessation of drainage indicates that it has healed. Radiological confirmation of healing should be obtained before the patient leaves hospital.

Where a diaphragmatic hernia is present segmental resection of the stomach and removal of the lower lobe of the left lung together with repair of the hernia as reported by Liavaag (1948) is probably the treatment of choice.

Gastro-bronchial fistulae developing in infiltrating carcinomata will rarely be treatable by surgical means since the parent tumour has usually reached an inoperable stage. However, it is theoretically possible for a carcinoma of the stomach infiltrating diaphragm and lung to be resectable and in such a case the lower lobe of the left lung, a portion of the diaphragm and the stomach would be removed en bloc.

Traumatic fistulae may be closed at once if diagnosed at initial laparatomy, but if they occur as a late complication of trauma they are probably best treated as already described for group 1 patients.

\section{Acknowledgments}

We are grateful to Professor E. F. Scowen and Mr M. H. Irving, under whose care this patient was admitted, for permission to publish details of the case. The radiograph and diagram were reproduced by the Department of Medical Illustration of St Bartholomew's Hospital.

\section{References}

AIrd, I. (1957) A Companion in Surgical Studies. 2nd Edition. Livingstone, London.
BeYe, H.I. (1932) The thoracic complications of subdiaphragmatic infection. Journal of Thoracic Surgery, 1, 655.

BOYD, D.P. (1959) The intrathoracic complications of subphrenic abscess. Journal of Thoracic and Cardiovascular Surgery, 38, 771 .

EFSKIND, L. (1953) Acquired non-malignant communications between the upper intestinal tract and the air passages. Acta chirurgica scandinavica, 105, 70.

GERICKE, W. (1957) Report on a traumatic gastrobronchial fistula. Fortschritte auf dem Gebiete der Roentgenstrahlen und der Nuklearmedizin, 86, 794.

Gimes, B. (1970) Gastrobronchiale fistel. Fortschritte auf dem Gebiete der Roentgenstrahlen und der Nuklearmedizin, 112 275.

Hathirat, S. (1969) Gastrobronchial fistula complicating subphrenic abscess. American Review of Respiratory Diseases, 99, 581.

JACKIEWICZ, Z., TomaszewSKi, J. \& ZdROJeWSKI, J. (1969) Gastrobronchial fistula as a complication of gastric ulcer. Polski Tygodnik Lekarski, 24, 1975.

LiavaAg, K. (1948) Gastro-bronchial fistula. Acta chirurgica scandinavica, 96, 425.

Mason, L.B. (1965) Subphrenic abscess-report of a case with fistulous connections to the stomach, colon and bronchus. The American Surgeon, 31, 278.

Milne, R.M. \& Thompson, J.W.W. (1970) A case of gastrobronchial fistula. British Journal of Surgery, 57, 632.

Moron, K., Bem, Z. \& WaWrykowicz, T. (1969) Ein Fall von Gastrobronchialfistel. Der Radiologe, 9, 85.

Ochsner, A. \& Graves, A.M. (1933) Subphrenic abscess. An analysis of 3372 collected and personal cases. Annals of Surgery, 98, 961.

SEYFORTH, K.A. (1959) Magen-Bronchial-Fistel nach traumatischer Zwerchfellruptur. Fortschritte auf dem Gebiete der Roentgenstrahlen und der Nuklearmedizin, 91, 408.

Urizza, J.L. \& Ramirez Gama, J. (1954) Fistula gastrobronquial consecutiva a hernia diafragmatica no traumatica. Revista Mexicana de Tuberculosis y Aparato Respiratorio.

WeTterfors, J. (1960) Complications of subphrenic abscess. Acta chirurgica scandinavica, 118, 409. 